\title{
Intracranial Epidermoid Lesions: Our Experience of 38 Cases
}

\author{
Lal REHMAN ${ }^{1}$, Iram BOKHARI ${ }^{1}$, Shamim UI Haq SIDDIQI'1 , Veejay BAGGA², Muhammad Masood HUSSAIN² \\ 1 Jinnah Postgraduate Medical Centre, Department of Neurosurgery, Karachi, Pakistan \\ ${ }^{2}$ Hull Royal Infirmary, Department of Neurosurgery, Hull, United Kingdom
}

\section{ABSTRACT}

AIM: To describe a case series evaluating the clinical presentation and outcome following surgery in patients diagnosed with these lesions.

MATERIAL and METHODS: A retrospective study conducted over a 4-year period.

RESULTS: A total 38 patients who underwent surgery for intracranial epidermoid lesions were identified. Of these, 20 were supratentorial and 18 were infratentorial lesions. Thirty-three patients presented with headache. Ten patients with supratentorial lesions presented with seizures. Patients with suprasellar epidermoid lesions presented with headache and visual problems. Fourteen of the 18 patients with cerebellopontine angle lesions presented with symptoms of trigeminal neuralgia. Postoperatively, 3 patients with cerebellopontine angle tumors developed facial weakness which was transient in 2 patients but permanent in 1 patient. Visual impairment in patients with suprasellar epidermoid lesions improved postoperatively. Hormonal replacement therapy was required in 2 patients. Recovery of 4 patients was complicated by cerebrospinal fluid leak while meningitis developed in 2 patients. One patient operated for cerebellopontine angle epidermoid died postoperatively.

CONCLUSION: Epidermoid lesions can develop anywhere in the cranial cavity. Like other space occupying lesions they often present with symptoms of raised intracranial pressure and with specific neurological deficits depending on location of the tumor. Surgical outcome is excellent with low complication rates.

KEYWORDS: Cerebellopontine angle, Complication, Epidermoid lesion, Surgical outcome.

ABBREVIATIONS: CSF: Cerebrospinal fluid, ICP: Intracranial pressure, MRI: Magnetic resonance imaging, CP: Cerebellopontine, DWI: Diffusion weighted imaging.

\section{INTRODUCTION}

I ntracranial epidermoid lesions are benign and account for $1 \%$ of all brain tumors (2). On the outside there is normal skin with stratified epithelium while on the inner side there is collection of keratin and fatty acid. Intracranially, they most commonly occur in the cerebellopontine (CP) angle, temporal region and suprasellar regions. Like other intracranial space occupying lesions they present with symptoms of raised intracranial pressure (ICP) or from focal neurological deficits secondary to mass effect or involvement of cranial nerves (4). For example, in suprasellar regions, patients present with visual problems and in temporal lobe lesions, patients often present with seizures. CP angle epidermoid lesions often present with facial pain and numbness.

Epidermoid lesions have an extremely slow linear growth rate (13), hence the duration of symptoms is prolonged and patients often present late (5). Magnetic resonance imaging (MRI) is the investigation of choice and diffusion weighted MRI plays an important role to differentiate it from arachnoid cyst. Surgery is the best option of treatment and has good results, however, the tumors are strongly adherent and residual capsule often remains after surgery resulting in recurrence (14). There is 
also a risk of chemical meningitis following surgery because of irritation caused by the cystic contents of the lesion. Total resection is therefore the aim of surgery; however this may not be possible without inducing severe neurological deficits(15).

The incidence of intracranial epidermoid lesions is rare and the clinical course following resection is not clearly documented. This study aims to evaluate the clinical outcome of patients following surgery.

\section{MATERIAL and METHODS}

This study was conducted at the Department of Neurosurgery, Jinnah Postgraduate Medical Centre, Karachi, from January 2011 to July 2015. A total of 38 patients were included in the study. All patients diagnosed with epidermoid lesions were included, apart from those presenting with recurrence. Patients had a craniotomy or craniectomy depending on whether the lesion was supratentorial or infratentorial respectively. Total resection was achieved in all cases. The operative site was washed with saline and all patients were given $1 \mathrm{~g}$ Ceftriaxone (Karachi, Pakistan) twice a day (BD) and Dexamethasone (Karachi, Pakistan) $4 \mathrm{mg}$ three times a day (TDS) for three days postoperatively. Patient data including history and presentation, examination findings, MRI findings, operative and histopathology findings was collected retrospectively. Data was analysed with the help of SPSS 20.

\section{RESULTS}

A total 38 patients were identified, 20 of which were male and 18 female (male: female ratio 2:1.8). The age ranged from 11 to 50 years with the average age of 27.89 years (Figure 1 ). Twenty patients had supratentorial lesions and 18 were located infratentorially. Of the supratentorial lesions, 4 patients had lesions located in the frontal lobe, 6 patients in the suprasellar region, and 10 in temporal lobe, with one temporal lobe lesion extending to the cavernous sinus and parietal lobe (Figure 2). All infratentorial lesions were located at the CP angle.
Thirty-three patients presented with headache, 10 patients had seizures and 14 patients with CP angle lesions presented with symptoms of trigeminal neuralgia (Figure 3).

All patients with suprasellar epidermoid lesions had visual field defects and two also had hormonal deficiency (one patient was deficient in thyroid and cortisol, while one patient had cortisol deficiency only). Two of the 10 patients with temporal region epidermoid lesions had mild weakness due to tumor extension to the motor strip and one patient had extension to the cavernous sinus and presented with third and sixth nerve palsy (Figure 3).

All patients underwent surgery. Postoperatively three patients with $\mathrm{CP}$ angle tumors had facial weakness. Two of them recovered after four months while one did not improve. Visual field defects in all patients with suprasellar epidermoid improved postoperatively. Two patients with suprasellar tumors required hormonal replacement.

Complications included cerebrospinal fluid (CSF) leak in four patients while two patients had postoperative meningitis. One patient with CP angle epidermoid died after surgery from a combination of intraoperative bleeding and postoperative meningitis (Figure 4).

\section{DISCUSSION}

Intracranial epidermoid lesions are slow growing congenital anomalies. The vast majority of patients remain clinically silent with only a select few having overt symptomatology (11). Signs and symptoms are due to gradual mass effect, with clinical presentation often manifesting as headaches, cranial nerve deficits, cerebellar symptoms and seizures (7). As a result of the slow growing nature of these lesions, clinical presentation (if at all) is often late and between the ages of 20 to 40 years $(6,21)$. This is consistent with our study which describes an average age of 27.9 years.

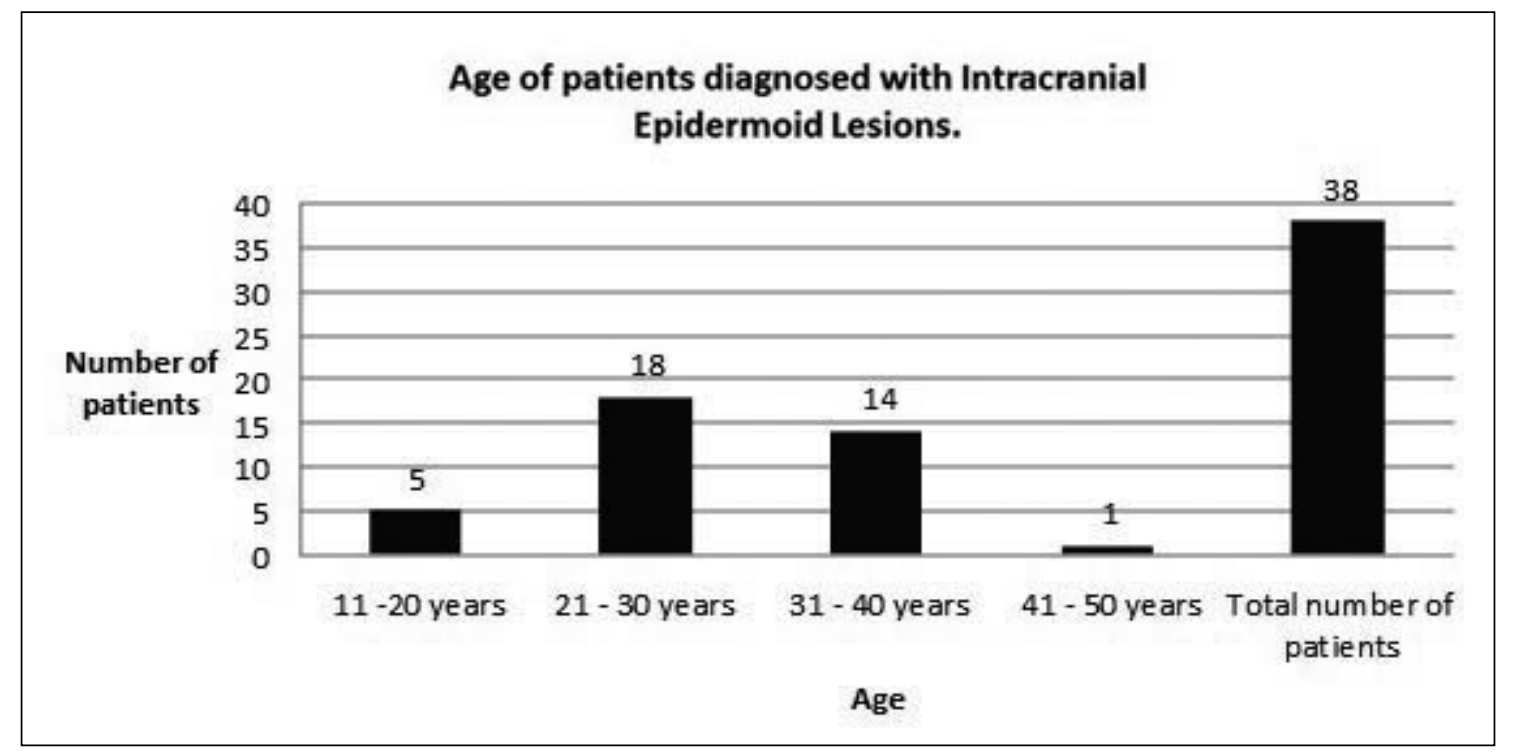

Figure 1: Age of patients diagnosed with intracranial epidermoid lesions. 

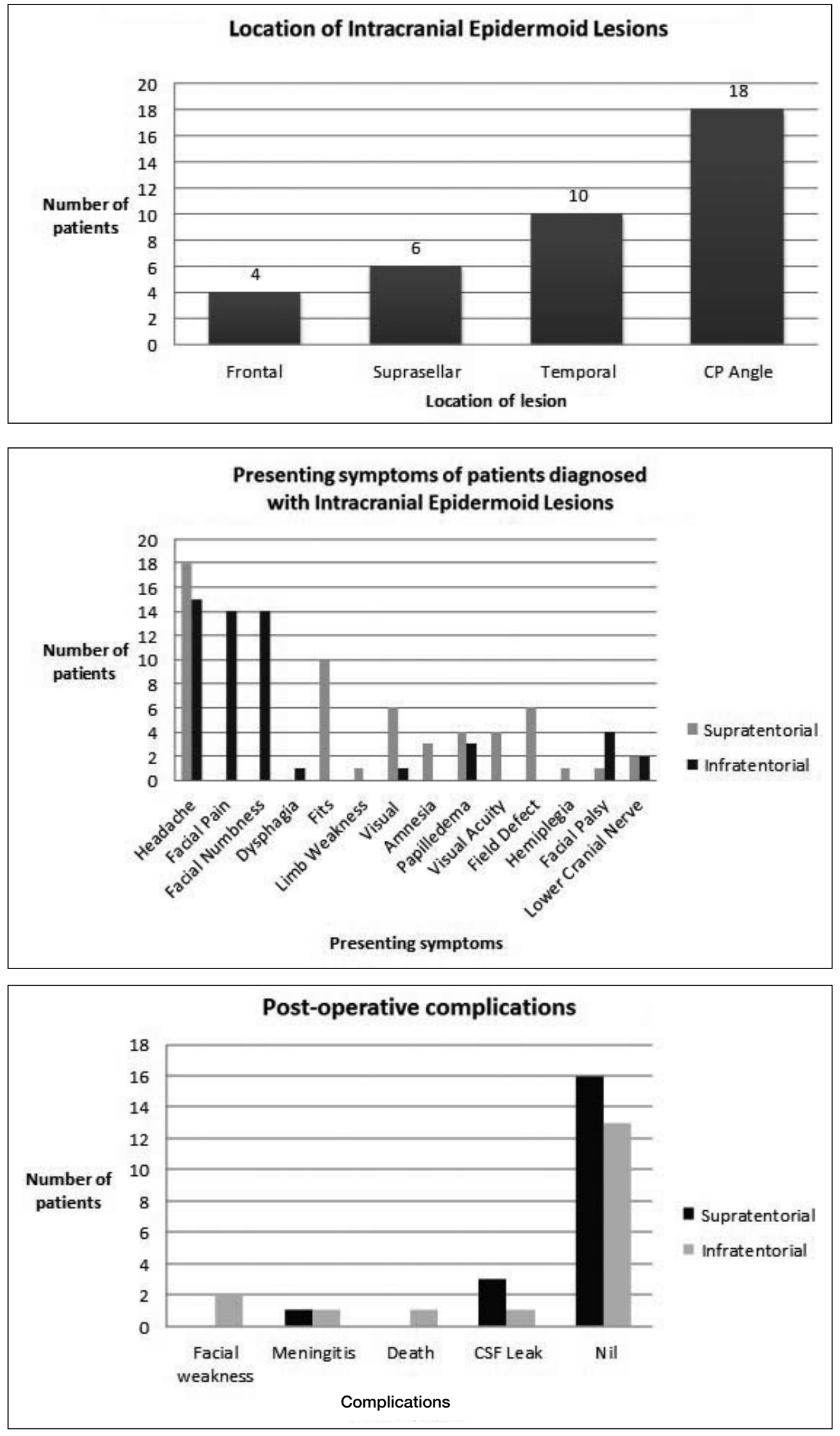

Figure 2: Location of intracranial epidermoid lesions.

Figure 3: Presenting symptoms of patients diagnosed with intracranial epidermoid lesions.

Figure 4: Postoperative complications. 
Epidermoid lesions have characteristic radiological features which help preoperative diagnosis. For example, these lesions typically appear as low-density lesions on computed tomography imaging (9), and restrict on MRI with diffusionweighted imaging (DWI). This is in contrast to arachnoid cysts which do not restrict because of free water molecules (13). Most epidermoid lesions do not enhance after injection of contrast agents, although minimal rim enhancement can occur in $25 \%$ of patients. This enhancement is generally attributed to peritumoral granulation secondary to leakage of irritant cyst contents (12). All images of patients in our study showed restricted diffusion on MRI with $\mathrm{DWI}$, therefore giving us confidence about the preoperative diagnosis.

For unknown reasons, intracranial epidermoid lesions are most commonly located in the CP angle. They are found in this location in $40-50 \%$ of patients with intracranial lesions (19) and represent $5-10 \%$ of all CP angle tumors. Our data is consistent with these documented findings as 18 of the 38 patients $(47.3 \%)$ had lesions which were in this location. In addition, these patients most commonly presented with hearing loss and trigeminal neuralgia (Figure 3 ) and again this is consistent with other documented cases (14).

Other common intracranial locations include the fourth ventricle $(17 \%)$, the parasellar regions (10-15\%), and less commonly the cerebral hemispheres and brainstem (9). The frontal lobe is an unusual location for epidermoid lesions and patients with frontal epidermoid tumors often present with seizures (10). In our study, there were a total of 4 cases with frontal epidermoids and all of them had seizures with neurological deficit. Intracerebral epidermoid tumors of the temporal lobe are exceedingly rare; however, we report 10 temporal lobe tumor cases in our series suggesting it is more common than originally thought.

Epidermoid cysts are circumscribed lesions with irregular lobulated surfaces that can grow and adhere to or encase vessels and nerves. Surgery is therefore challenging and incomplete resection is common because of the association with vital structures such as cranial nerves or the brainstem. While gross total resection of these tumors offers definitive treatment to prevent recurrence and provide a normal life expectancy (4), it can carry a high risk of morbidity. A subtotal resection may therefore be necessary to preserve neurological function $(18,20)$.

The postoperative complication rate in our series was $21.05 \%$ (8/38 patients) with mortality of $2.36 \%$ (1/38 patients-Figure 4). Similar values have been reported previously $(1,16)$. Prior to the microsurgical era, operative mortality ranged from $20 \%$ to $57 \%$. With the advancement in neuroimaging and microsurgical techniques, surgery-induced mortality is now significantly lower.

Two patients in our study were diagnosed with postoperative meningitis. It is unclear whether this was bacterial meningitis or chemical meningitis which is a recognised complication. Chemical aseptic meningitis can be the first rare clinical manifestation of these tumors and this can also occur postoperatively. The keratinous cystic contents are incriminated to be responsible for the inflammatory reaction resulting in the meningitis. The pathological reaction to the irritants ranges from mild leptomeningitis to widespread granulomatous meningitis, ependymitis, and posterior radiculitis. Since chemical and bacterial meningitis may coexist, it is safer to start antibiotic therapy initially since the spinal fluid profiles in bacterial and chemical meningitis are similar (3).

Associated hydrocephalus is said to be uncommon because of the long-standing nature of the lesion and also because CSF permeates through the crevices of the lesions. However, in the present study, $50 \%$ of the patients had ventriculomegaly and four of them required preoperative CSF diversion procedures in the form of a ventriculoperitoneal shunt. Another patient required shunting postoperatively period because of a CSF leak. In a previously reported series, 12 of 30 patients with CP angle epidermoid lesions required shunt surgery for hydrocephalus (17).

\section{- CONCLUSION}

Epidermoid lesions are slow grown benign lesions which can occur at any location within the brain. Clinical presentation often reflects symptoms of raised ICP or is due to focal neurological deficits secondary to local mass effect exerted by the tumor. Total resection is the aim of surgery and recovery is excellent with low postoperative complication rates following resection.

\section{- REFERENCES}

1. Ali M, Khanzada K, Khan H, Ayub S, Mehmood K, Roghani IS, Rehmam S: Cranial dermoid and epidermoid tumors. J Postgrad Med Inst 22(1):33-36, 2008

2. Chen CY, Wong JS, Hsieh SC, Chu JS, Chan WP: Intracranial epidermoid cyst with hemorrhage: MR imaging findings. Am J Neuroradiol 27(2):427-429, 2006

3. Cherian A, Baheti NN, Easwar HV, Nair DS, lype T: Recurrent meningitis due to epidermoid. J Pediatr Neurosci 7(1):47-48, 2012

4. Chowdhury FH, Haque MR, Sarker MH: Intracranial epidermoid tumor; microneurosurgical management: An experience of 23 cases. Asian J Neurosurg 8(1):21-28, 2013

5. Coskun E, Acar F, Suzer T, Çirak B: Hypertrophic cranial pachymeningitis after Mollaret's Meningitis: Case report and review of the literature. J Neurol Sci (Turk) 24:331-337, 2007

6. DeMonte F, Gilbert MR, Mahajan A, McCutcheon E: Tumors of the brain and spine. Springer Verlag, 2007

7. deSouza CE, deSouza R, da Costa S, Sperling N, Yoon TH, Abdelhamid MM, Sharma RR, Goel A: Cerebellopontine angle epidermoid cysts: A report on 30 cases. J Neurol Neurosurg Psychiatry 52(8):986-990, 1989

8. Gao PY, Osborn AG, Smirniotopoulos JG, Harris CP: Radiologic-pathologic correlation. Epidermoid tumor of the cerebellopontine angle. AJNR Am J Neuroradiol 13(3):863782, 1992

9. Guo Z, Ouyang H, Cheng Z: Surgical treatment of parapontine epidermoid cysts presenting with trigeminal neuralgia. J Clin Neurosci 18(3):344-346, 2011 
10. Hamada $Y$, Kishi H, Matsuo S: Intraparenchymal epidermoid cyst of the right frontal lobe: A case report. No Shinkei Geka 13(6):695-699, 1985 (In Japanese)

11. Hanft SJ, Komotar RJ, Raper DM, Sisti MB, McKhann GM $2^{\text {nd }}$ : Epidermoid tumors of the temporal lobe as epileptogenic foci. J Clin Neurosci 18(10):1396-1399, 2011

12. Inoue $Y$, Ohata K, Nakayama K, Haba T, Shakudo M: An unusual middle fossa interdural epidermoid tumor. Case report. J Neurosurg 95(5):902-904, 2001

13. Jolapara M, Kesavadas C, Radhakrishnan VV, Saini J, Patro SN, Gupta AK, Kapilamoorthy TR, Bodhey N: Diffusion tensor mode in imaging of intracranial epidermoid cysts: One step ahead of fractional anisotropy. Neuroradiology 51(2):123-129, 2009

14. Kato K, Ujiie H, Higa T, Hayashi M, Kubo O, Okada Y, Hori $\mathrm{T}$ : Clinical presentation of intracranial epidermoids: A surgical series of 20 initial and four recurred cases. Asian J Neurosurg 5(1):32-40, 2010

15. Kobata $\mathrm{H}$, Kondo $\mathrm{A}$, Iwasaki $\mathrm{K}$ : Cerebellopontine angle epidermoids presenting with cranial nerve hyperactive dysfunction: Pathogenesis and long-term surgical results in 30 patients. Neurosurgery 50(2):276-285, 2002
16. Lopes M, Capelle L, Duffau H, Kujas M, Sichez JP, Van Effenterre R, Faillot T, Bitar A, Fohanno D: Surgery of intracranial epidermoid cysts. Report of 44 patients and review of the literature. Neurochirurgie 48(1):5-13, 2002

17. Mohanty A, Venkatrama SK, Rao BR, Chandramouli BA, Jayakumar PN, Das BS: Experience with cerebellopontine angle epidermoids. Neurosurgery 40(1):24-29, 1997

18. Nagasawa D, Yew A, Safaee M, Fong B, Gopen Q, Parsa AT, Yang I: Clinical Characteristics and diagnostic imaging of epidermoid tumors. J Clin Neurosci 18(9):1158-1162, 2011

19. Osborn AG, Preece MT: Intracranial cysts: Radiologicpathologic correlation and imaging approach. Radiology 239(3):650-664, 2006

20. Samii M, Tatagiba M, Piquer J, Carvalho GA: Surgical treatment of epidermoid cysts of the cerebellopontine angle. J Neurosurg 84(1):14-19, 1996

21. Yasargil MG, Abernathey CD, Sarioglu AC: Microneurosurgical treatment of intracranial dermoid and epidermoid tumors. Neurosurgery 24(4):561-567, 1989 